\title{
Message from the President of the Biophilia Rehabilitation Academy of Japan
}

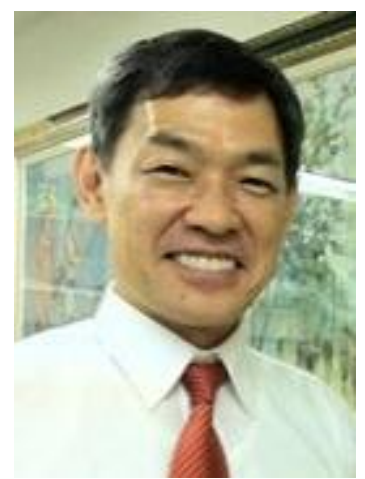

Takuji shirasawa, MD., Ph.D.

President of the Biophilia Rehabilitation Academy of Japan

Prof.Department of Aging Control Medicine

Graduate School of Medicine of Juntendo University

Learning gives creativity, creativity leads to thinking, thinking provides knowledge, and knowledge makes you great! This is what BIOPHILIA Rehabilitation Academy stands for. The name in itself literally means the love of life and all living systems "bio" + "philia". The biophilia hypothesis suggests that there is an instinctive bond between human beings and other living systems. In accordance to its name, this organization functions to improve the life of the handicapped people in Japan and around the world, giving them hope and actively contributing to improving their quality of life. The journal "Biophilia" is an academic medical journal if the International Biophilia Rehabilitation Academy that is aiming at revolutionizing rehabilitation medicine.

The International Biophilia Rebahilitation Academy periodically holds international congresses abroad Japan actively contribution to the people's welfare around the world. The activity for the functional recovery of advanced-age disabled persons is well appreciated by the governments of the countries visited:

2013 The $10^{\text {th }}$ Conference in Italy

2011 The $9^{\text {th }}$ Conference, in Romania and Poland

2010 The $8^{\text {th }}$ Conference in China

2009 The $7^{\text {th }}$ Conference in Cuba

2008 The $6^{\text {th }}$ Conference in Poland

2006 The $5^{\text {th }}$ Conference in Australia

2005 The $4^{\text {th }}$ Conference in Germany

2004 The $3^{\text {rd }}$ Conference in Philippines

2003 The $2^{\text {nd }}$ Conference in Candada

2002 The $1^{\text {st }}$ Conference in Saipan the Commonwealth of the Northern Mariana Islands

2001 Domestic Conference in Tokyo at Nippon Medical School

The workshop "Biophilia 2013" of "The $10^{\text {th }}$ International Biophilia Rehabilitation Conference" will be/was held in Chieti, Italy at the University of Chieti.

The Scientific Committee always prepares a diverse scientific program structured around the theme of rehabilitation. Not only that the conferences address psychological and physical aspects of rehabilitation but also longevity and healthy aging through exercise, healthy lifestyle, eating habits and choices of the right ingredients such as salt, sugar, oil, and supplements thus preventing deterioration of quality of life.

I hope the discussion and studies to be of great value for the debilitated people and for the future of the rehabilitation medicine. 